\title{
Cyclin D1 Expression and Its Correlation with Histopathological Differentiation in Oral Squamous Cell Carcinoma
}

\author{
Swati Saawarn, ${ }^{1}$ Madhusudan Astekar, ${ }^{2}$ Nisheeth Saawarn, ${ }^{3}$ Nidhi Dhakar, ${ }^{4}$ \\ and Shitalkumar Gomateshwar Sagari ${ }^{5}$ \\ ${ }^{1}$ Department of Oral Pathology and Microbiology, Peoples Dental Academy, Bhanpur, Bhopal 462037, MP, India \\ ${ }^{2}$ Department of Oral Pathology and Microbiology, Pacific Dental College and Hospital, Udaipur 313024, India \\ ${ }^{3}$ Department of Oral Medicine and Radiology, Peoples College of Dental Sciences, Bhopal 462037, India \\ ${ }^{4}$ Department of Oral Pathology and Microbiology, Darshan Dental College and Hospital, Udaipur 313011, India \\ ${ }^{5}$ Deprtment of Oral Pathology and Microbiology, Jodhpur Dental College and Hospital, Jodhpur 342001, India
}

Correspondence should be addressed to Swati Saawarn, drswatisaawarn@gmail.com

Received 15 October 2011; Accepted 23 November 2011

Academic Editors: S. Staibano and S. Strano

Copyright (C) 2012 Swati Saawarn et al. This is an open access article distributed under the Creative Commons Attribution License, which permits unrestricted use, distribution, and reproduction in any medium, provided the original work is properly cited.

\begin{abstract}
Background. Cyclin D1 regulates the G1 to S transition of cell cycle. Its deregulation or overexpression may lead to disturbance in the normal cell cycle control and tumour formation. Overexpression of cyclin D1 has been reported in various tumors of diverse histogenesis. This case control retrospective study was carried out to study the immunohistochemical reactivity and expression of cyclin D1 and its association with site, clinical staging, and histopathological differentiation of oral squamous cell carcinoma (OSCC). Methods. Forty formalin-fixed paraffin-embedded tissue blocks of biopsy specimens of oral squamous cell carcinoma were immunohistochemically evaluated for expression of cyclin D1. Results. Cyclin D1 expression was seen in 45\% cases of OSCC. It did not correlate with site and clinical staging. Highest expression was seen in well-differentiated, followed by moderately differentiated, and poorly differentiated squamous cell carcinomas, with a statistically significant correlation. Conclusion. Cyclin D1 expression significantly increases with increase in differentiation.
\end{abstract}

\section{Introduction}

The multistage process of carcinogenesis involves the progressive acquisition of mutations and epigenetic abnormalities in the expression of multiple genes, with an important group among them being those involved in cell cycle control $[1]$.

The orderly progression of the cells through the various phases of cell cycle, namely, G1, S, G2, and M phases is precisely governed by a series of proteins called "cyclins," which exert their effect by binding and activating the cyclin-dependent kinases (CDK) [2].

Cyclin D1, a $45 \mathrm{kD}$ (kilo Dalton) protein encoded by cyclin D1 gene (CCND1) located on chromosome 11q13, is a part of the molecular system that regulates the cell cycle $\mathrm{G} 1$ to $S$ transition [2]. It was first isolated as Parathyroid adenomatosis 1 gene (PRAD1) oncogene clonally rearranged and overexpressed in parathyroid adenomas and is identical to B-cell lymphomal gene (bcl-1) protoncogene, which is translocated and overexpressed in a subset of B-cell neoplasms [1].

Overexpression of cyclin D1 leads to shortening of G1 phase and less dependency on growth factors resulting in abnormal cell proliferation which in turn might favour the occurrence of additional genetic lesions [1].

Cyclin D1 expression has been studied in various carcinomas including oral squamous cell carcinomas. Some studies have been carried out to correlate the expression of cyclin D1 with histological grading of this neoplasm [2-5]. However, the results have not been consistent and conclusive.

Hence, this retrospective laboratory-based study was undertaken to study the expression of cyclin D1 in oral squamous cell carcinoma and to correlate its expression with histological differentiation. 


\section{Materials and Methods}

Forty formalin-fixed paraffin-embedded (FFPE) tissue blocks of incisional biopsy specimens, which were histologically diagnosed as oral squamous cell carcinoma (OSCC), were retrieved from the archives of Department of Oral and Maxillofacial Pathology of the Pacific Dental College, Udaipur, India. One FFPE tissue block of normal oral mucosa was included as a positive control and one squamous cell carcinoma tissue with exclusion of primary antibody was used as negative control.

From each FFPE tissue block, 3-4 $\mu$ thick sections were cut and stained by H\&E stain for histopathological grading. Tumours were graded according to Broder's criteria [6] into well- (WDSCC; $n=13$ ), moderately (MDSCC; $n=16$ ), and poorly differentiated (PDSCC; $n=11$ ) ones.

Immunohistochemical study was carried out using polymer-labelling technique (Dako, Envision). Sections were dewaxed, washed in alcohol and antigen retrieval was carried out in a Decloaking Chamber (Pascal) with $10 \mathrm{mM}$ Citra solution at $125^{\circ} \mathrm{C}$ for 30 seconds followed by $90^{\circ} \mathrm{C}$ for $10 \mathrm{sec}-$ onds. Slides were cooled naturally and brought to room temperature. Slides were placed inside the Dako Autostainer Universal Staining System, an automated immunohistochemistry staining system. Endogenous peroxidase was blocked by using $0.3 \%$ hydrogen peroxide in methanol at room temperature for 10 minutes. Slides were washed with phosphate-buffered saline (PBS) briefly and incubated with primary antibody (Cyclin D1) for 60 minutes. Section were again washed with PBS, incubated with the polymer for 30 minutes, and washed again with PBS. Diaminobenzidine (DAB) was used as the chromogen in hydrogen peroxide for 10 minutes. Sections were then counterstained with haemotoxylin, mounted, and studied under light microscope for immunorecativity.

Presence of brown-coloured end product at the site of target antigen was indicative of positive immunoreactivity. The negative control demonstrated the absence of staining. Tissue section of positive control showed brown staining of the cells of basal and parabasal layers and was confirmed as being positively stained (Figure 1). The evaluation of study cases was done subsequently in a similar way for IHC reactivity. Only the slides showing positive reactivity were further evaluated for cyclin D1 expression as per criteria described by $\mathrm{Gu}$ et al. [7].

In every slide ten, hot spot areas were selected and observed under higher (400X) magnification with a grid. Percentage of IHC positive tumour cells per hot spot was calculated and the mean percentage per slide (labelling index) was determined (Figure 2). A labelling index score of 1, 2, 3, or 4 was assigned for labelling indices 1-25\%, 26-50\%, 51-75\%, and $>75 \%$, respectively.

The intensity of cyclin D1 immunostaining (Figure 3) was evaluated on the basis of microscopic appearance as weak, intermediate, or strong and an intensity score of 1, 2, or 3 was assigned to them, respectively.

A final expression score was calculated by multiplying labelling index score with intensity score, based on which the cyclin D1 expression was determined as weak (score 14 ), moderate (score 5-8), or strong (score 9-12).

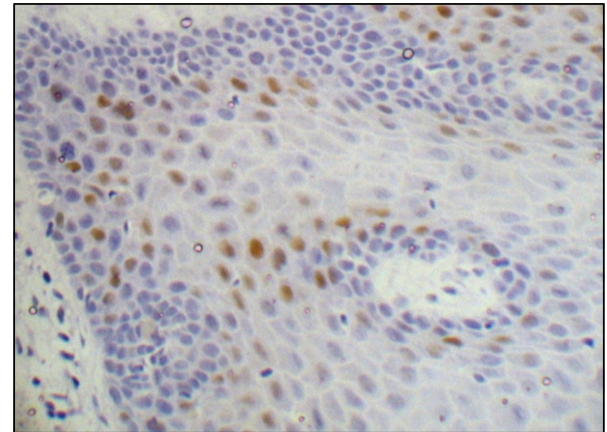

Figure 1: Photomicrograph depicting Cyclin D1 expression in basal and suprabasal layers of normal epithelium.

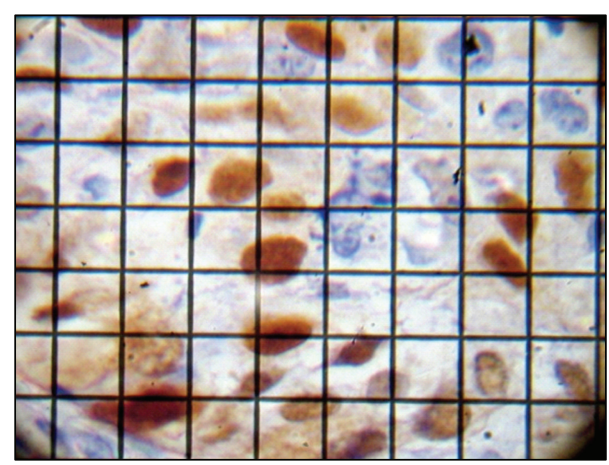

FIGURe 2: Photomicrograph depicting labelling index calculation under high magnification with a grid.

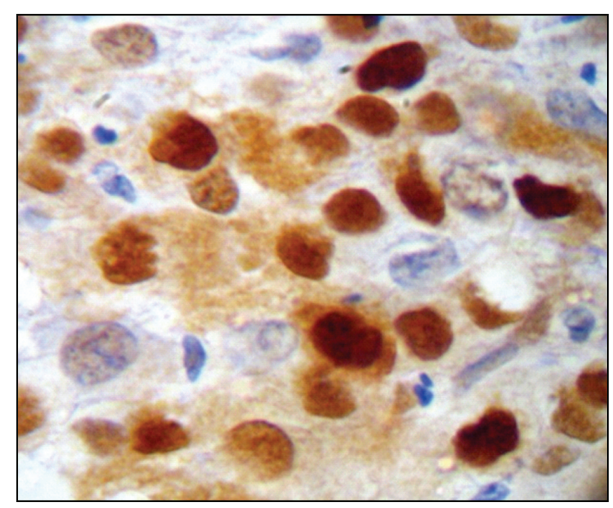

Figure 3: Photomicrograph depicting intensity evaluation under high magnification.

All the relevant clinical, histopatholocal, and immunohistochemical data so obtained were tabulated and subjected to appropriate statistical analysis using the SPSS 11 statistical software.

\section{Results}

Cyclin D1 positivity was seen in 18 cases (45\%) of OSCC. Further distribution of cyclin D1 reactivity in accordance with site, clinical stage, and histopathological differentiation are explained in Table 1. The labelling index scores, intensity 
TABLE 1: Distribution of site, clinical staging, histopathological differentiation of OSCC, and their IHC reactivity.

\begin{tabular}{|c|c|c|c|c|c|}
\hline \multirow{2}{*}{ Distribution category } & \multirow{2}{*}{ Total number } & \multicolumn{4}{|c|}{ IHC reactivity } \\
\hline & & $\begin{array}{l}\text { Positive } \\
(n)\end{array}$ & $\begin{array}{l}\text { Negative } \\
(n)\end{array}$ & $\begin{array}{l}\% \text { of positive } \\
\text { reactivity }\end{array}$ & $P$ \\
\hline \multicolumn{6}{|l|}{ Site } \\
\hline Alveolus & 11 & 07 & 04 & 63.63 & \multirow{4}{*}{$\begin{array}{l}0.282 \\
\text { NS }\end{array}$} \\
\hline Buccal mucosa & 13 & 05 & 08 & 38.46 & \\
\hline Tongue & 15 & 05 & 10 & 33.33 & \\
\hline Lip & 01 & 01 & 00 & 100 & \\
\hline \multicolumn{6}{|l|}{ Clinical staging } \\
\hline Stage I & 06 & 03 & 03 & 50 & \multirow{4}{*}{$\begin{array}{c}0.867 \\
\text { NS }\end{array}$} \\
\hline Stage II & 07 & 04 & 03 & 57.14 & \\
\hline Stage III & 13 & 05 & 08 & 38.4 & \\
\hline Stage IV & 14 & 06 & 08 & 42.8 & \\
\hline \multicolumn{6}{|l|}{$\begin{array}{l}\text { Histopathological } \\
\text { differentiation }\end{array}$} \\
\hline WDSCC & 13 & 09 & 04 & 69.23 & \multirow{3}{*}{$0.011 \mathrm{~S}$} \\
\hline MDSCC & 16 & 08 & 08 & 50 & \\
\hline PDSCC & 11 & 01 & 10 & 9.09 & \\
\hline OSCC (total) & 40 & 18 & 22 & 45 & \\
\hline
\end{tabular}

TABLE 2: Labelling index score, and intensity in relation to histopathological differentiation.

\begin{tabular}{lccccccccc}
\hline \multirow{2}{*}{ OSCC differentiation } & \multicolumn{4}{c}{ Intensity } & \multicolumn{4}{c}{ Labelling index score } \\
& Weak $(n)$ & Intermediate $(n)$ & Strong $(n)$ & $P$ & Score 1 & Score 2 & Score 3 & Score 4 & $P$ \\
\hline WDSCC & 4 & 3 & 2 & 0.075 & 1 & 5 & 3 & 0 & 0.361 \\
MDSCC & 2 & 4 & 2 & $(\mathrm{NS})$ & 1 & 1 & 6 & 0 & $(\mathrm{NS})$ \\
PDSCC & 0 & 0 & 1 & & 0 & 0 & 0 & 1 & \\
\hline OSCC & 6 & 7 & 5 & & 2 & 6 & 9 & 1 \\
\hline
\end{tabular}

Table 3: Cyclin D1 expression in relation to site, clinical staging, and histopathological distribution.

\begin{tabular}{|c|c|c|c|c|c|}
\hline \multirow{2}{*}{ Distribution category } & \multicolumn{5}{|c|}{ Cyclin D1 expression } \\
\hline & Weak $(n)$ & $\begin{array}{l}\text { Moderate } \\
(n)\end{array}$ & Strong $(n)$ & $P$ & \\
\hline \multicolumn{6}{|l|}{ Site } \\
\hline Alveolus & 04 & 01 & 02 & \multirow{4}{*}{$0.255 \mathrm{I}$} & \\
\hline Buccal mucosa & 01 & 02 & 02 & & NS \\
\hline Tongue & 04 & 00 & 01 & & \\
\hline Lip & 00 & 01 & 00 & & \\
\hline \multicolumn{6}{|l|}{ Clinical Staging } \\
\hline Stage I & 01 & 01 & 01 & \multirow{4}{*}{0.866} & \\
\hline Stage II & 03 & 01 & 00 & & NS \\
\hline Stage III & 02 & 01 & 02 & & \\
\hline Stage IV & 03 & 01 & 02 & & \\
\hline \multicolumn{6}{|l|}{$\begin{array}{l}\text { Histopathological } \\
\text { differentiation }\end{array}$} \\
\hline WDSCC & 07 & 00 & 02 & \multirow{3}{*}{\multicolumn{2}{|c|}{$0.042 \mathrm{~S}$}} \\
\hline MDSCC & 02 & 04 & 02 & & \\
\hline PDSCC & 00 & 00 & 01 & & \\
\hline OSCC (total) & 09 & 04 & 05 & & \\
\hline
\end{tabular}


of staining, expressions graded, and their correlations with clinical and histological parameters are elaborated in Tables 2 and 3 .

Both cyclin D1 reactivity and expression did not show any correlation with site and clinical staging of the OSCC (Tables 1 and 3). The histopathological differentiation showed a positive correlation with increase in both the reactivity and expression with increasing differentiation (Tables 1 and 3 ). The labelling index score and intensity did not correlate with OSCC differentiation (Table 2).

\section{Discussion}

The present study was carried out to study the immunohistochemical reactivity and expression of cyclin D1 and its association with site, clinical staging, and histopathological differentiation of oral squamous cell carcinoma.

The IHC reactivity for cyclin D1 was evaluated on the basis of presence or absence of brown staining. Nuclear and cytoplasmic stainings in all the cases of positivity were observed, which was similar to other studies [3, 4, 7-19]. However, Gillett et al. [20] considered only cytoplasmic staining as negative, and Vora et al. [5] reported exclusively cytoplasmic staining in their cases and considered the same as positive.

De Falco et al. have stated that in adult tissues, cyclin D1 plays a role in proliferation and differentiation and the shift between nucleus and cytoplasm is necessary to regulate finely the passage across different phases of the cell cycle. The immunogold observations have indicated transit of cyclin D1 between nuclear and cytoplasmic compartments via nuclear pores [17].

In the present study, cyclin D1 reactivity was seen in $45 \%$ of cases. Some authors have reported less than $45 \%$ reactivity $[4,8,9,13-16,21]$ while some have shown more $[2,3,5$, $10,12,16,22-25]$. These reported variations in reactivity may be due to diverse reasons like asymmetric labelling expression seen in different parts of same specimen owing to the fact that in a specimen at a given time, only about $20 \%$ of the neoplastic cells are under mitosis [8]. A discrepancy in staining between the biopsy and surgical resection materials has also been reported, most likely owing to tissue heterogeneity [26]. Further, cyclin D1 has been described to express itself mainly in the peripheral layers of tumour islands and not in the cells exhibiting mitosis [3]. The pRb gene also appears to regulate transcription of the cyclin D1 which is destabilized in pRb-negative cells and hence cells negative for $\mathrm{pRb}$ staining do not express cyclin D1; this may be due to the fact that sometimes cyclin D1 acts as a negative regulator of cell cycle progression [20]. Bartkova et al. reported that in several common solid tumours, cyclin D1 protein may be essential for G1 phase progression while some may have lost thier requirement [27]. Further, an inverse relationship of HPV status has also been reported with cyclin D1 expression in OSCC [18].

To determine the cyclin D1 expression, we used a more objective and inclusive method, as depicted by $\mathrm{Gu}$ et al. [7] by multiplying the intensity score with labelling index score. Whereas a few authors have used only a subjective evaluation of intensity at three point criteria as "weak, moderate, and strong" $[2,4,28]$ or two point criteria as "weak and strong" $[21,29]$ and considered it as final expression. While some other investigators have used labelling index score only as final expression $[3,5,9,10,12,14-16,21,23,24,30]$. Maahs et al. used stereologic method to determine labelling index [8].

In our study, the labelling index did not have any correlation with histopathological differentiation and the results could not be compared directly with other reported literatures, because of different criteria used for determining scores by different authors $[3,5,9,10,12,14-16,21,23,24$, 30].

The staining intensity was nonuniform, showing maximum cases of intermediate staining followed by weak and strong. Angadi and Krishnapillai [2] and Mishra and Das [4] noted a uniformly increasing intensity in relation to the histopathological differentiation, whereas Castle et al. [28] found no correlation.

In the present study, the cyclin D1 expression shown by maximum number of cases was weak, followed by strong, and intermediate. The expression had a significant correlation with histological differentiation. There was an increase in cyclin D1 expression with increasing differentiation, that is, highest expression was seen in WDSCC, followed by MDSCC, and PDSCC. Since no studies on OSCC are available in the literature using the similar criteria for determining expression as used in the present study, we cannot directly compare this data with that of others.

Many studies have been done on cyclin D1 in OSCC, and even though the controversy exists in the scientific literature, it opens a window of opportunity for further discussion and research in different tumours with additional different criteria like lymph node involvement and metastasis. The interpretation of the above study is precluded by its limited sample size and therefore the study should be followed further with large sample size to validate our finding. The observations in this field may contribute significantly to the patient well-being and decreased morbidity and mortality by establishing cyclin D1 as a better prognostic marker.

\section{References}

[1] R. Todd, P. W. Hinds, K. Munger et al., "Cell cycle dysregulation in oral cancer," Critical Reviews in Oral Biology and Medicine, vol. 13, no. 1, pp. 51-61, 2002.

[2] P. V. Angadi and R. Krishnapillai, "Cyclin D1 expression in oral squamous cell carcinoma and verrucous carcinoma: correlation with histological differentiation," Oral Surgery, Oral Medicine, Oral Pathology, Oral Radiology and Endodontology, vol. 103, no. 3, pp. e30-e35, 2007.

[3] A. D. C. Neves, R. A. Mesquita, M. D. Novelli, E. Toddai, and S. O. M. De Sousa, "Comparison between immunohistochemical expression of cyclin D1 and p21 and histological malignancy graduation of oral squamous cell carcinomas," Brazilian Dental Journal, vol. 15, no. 2, pp. 93-98, 2004.

[4] R. Mishra and B. R. Das, "Cyclin D1 expression and its possible regulation in chewing tobacco mediated oral squamous cell carcinoma progression," Archives of Oral Biology, vol. 54, no. 10, pp. 917-923, 2009. 
[5] H. H. Vora, N. G. Shah, T. T. Trivedi et al., "Cyclin D1 expression in prediction of survival in carcinoma of the tongue," GCRI Bulletin, vol. 7, pp. 130-135, 1997.

[6] G. Anneroth, J. Batsakis, and M. Luna, "Review of the literature and a recommended system of malignancy grading in oral squamous cell carcinomas," Scandinavian Journal of Dental Research, vol. 95, no. 3, pp. 229-249, 1987.

[7] Y. Gu, S. Zhang, Q. Wu et al., "Differential expression of decorin, EGFR and cyclin D1 during mammary gland carcinogenesis in TA2 mice with spontaneous breast cancer," Journal of Experimental and Clinical Cancer Research, vol. 22, pp. 2936, 2010.

[8] G. S. Maahs, D. C. Machado, E. A. Jeckel-Neto, and V. S. Michaelses, "Cyclin D1 expression and cervical metastases in squamous cell carcinoma of the mouth," Brazilian Journal of Otorhinolaryngology, vol. 73, no. 1, pp. 93-100, 2007.

[9] J. Xu, I. B. Gimenez-Conti, J. E. Cunningham et al., "Alterations of p53, cyclin D1, Rb, and H-ras in human oral carcinomas related to tobacco use," Cancer, vol. 83, no. 2, pp. 204-212, 1998.

[10] E. Turatti, A. da Costa Neves, M. H. de Magalhães, and S. O. de Sousa, "Assessment of c-Jun, c-Fos and cyclin D1 in premalignant and malignant oral lesions," Journal of Oral Science, vol. 47, no. 2, pp. 71-76, 2005.

[11] M. Woods, R. Pant, and S. M. Mallya, "Cyclin D1 and cyclin D-dependent kinases enhance oral keratinocyte proliferation but do not block keratinocyte differentiation," International Journal of Oncology, vol. 37, no. 6, pp. 1471-1475, 2010.

[12] H. Goto, K. Kawano, I. Kobayashi, H. Sakai, and S. Yanagisawa, "Expression of cyclin D1 and GSK-3 $\beta$ and their predictive value of prognosis in squamous cell carcinomas of the tongue," Oral Oncology, vol. 38, no. 6, pp. 549-556, 2002.

[13] A. Rousseau, M. S. Lim, Z. Lin, and R. C. K. Jordan, "Frequent cyclin D1 gene amplification and protein overexpression in oral epithelial dysplasias," Oral Oncology, vol. 37, no. 3, pp. 268-275, 2001.

[14] S. Shintani, M. Mihara, Y. Nakahara et al., "Expression of cell cycle control proteins in normal epithelium, premalignant and malignant lesions of oral cavity," Oral Oncology, vol. 38, no. 3, pp. 235-243, 2002.

[15] M. L. Schoelch, J. A. Regezi, N. P. Dekker et al., "Cell cycle proteins and the development of oral squamous cell carcinoma," Oral Oncology, vol. 35, no. 3, pp. 333-342, 1999.

[16] K. Y. Lam, O. L. Irene, A. P. W. Yuen, D. L. W. Kwong, and W. Wei, "Cyclin D1 expression in oral squamous cell carcinomas: clinicopathological relevance and correlation with p53 expression," Journal of Oral Pathology and Medicine, vol. 29, no. 4, pp. 167-172, 2000.

[17] M. De Falco, V. Fedele, L. D. Luca et al., "Evaluation of cyclin D1 expression and its subcellular distribution in mouse tissues," Journal of Anatomy, vol. 205, no. 5, pp. 405-412, 2004.

[18] C. J. Marsit, C. C. Black, M. R. Posner, and K. T. Kelsey, "A genotype-phenotype examination of cyclin D1 on risk and outcome of squamous cell carcinoma of the head and neck," Clinical Cancer Research, vol. 14, no. 8, pp. 2371-2377, 2008.

[19] C. Gillett, V. Fantl, R. Smith et al., "Amplification and overexpression of cyclin D1 in breast cancer detected by immunohistochemical staining," Cancer Research, vol. 54, no. 7, pp. 1812-1817, 1994.

[20] C. Gillett, P. Smith, W. Gregory et al., "Cyclin D1 and prognosis in human breast cancer," International Journal of Cancer, vol. 69, no. 2, pp. 92-99, 1996.
[21] J. Carlos De Vicente, A. Herrero-Zapatero, M. F. Fresno, and J. S. López-Arranz, "Expression of cyclin D1 and Ki-67 in squamous cell carcinoma of the oral cavity: clinicopathological and prognostic significance," Oral Oncology, vol. 38, no. 3, pp. 301$308,2002$.

[22] R. Miyamoto, N. Uzawa, S. Nagaoka, Y. Hirata, and T. Amagasa, "Prognostic significance of cyclin D1 amplification and overexpression in oral squamous cell carcinomas," Oral Oncology, vol. 39, no. 6, pp. 610-618, 2003.

[23] M. Y. P. Kuo, C. Y. Lin, L. J. Hahn, S. J. Cheng, and C. P. Chiang, "Expression of cyclin D1 is correlated with poor prognosis in patients with areca quid chewing-related oral squamous cell carcinomas in Taiwan," Journal of Oral Pathology and Medicine, vol. 28, no. 4, pp. 165-169, 1999.

[24] S. Koontongkaew, L. Chareonkitkajorn, A. Chanvitan, M. Leklakriangrak, and P. Amornphimoltham, "Alterations of p53, pRb, cyclin D1 and cdk4 in human oral and pharyngeal squamous cell carcinomas," Oral Oncology, vol. 36, no. 4, pp. 334-339, 2000.

[25] N. Uzawa, I. Sonoda, K. Myo et al., "Fluorescence in situ hybridization for detecting genomic alterations of cyclin D1 and p16 in oral squamous cell carcinomas," Cancer, vol. 110, no. 10, pp. 2230-2239, 2007.

[26] R. J. A. M. Michalides, N. M. J. Van Veelen, P. M. P. Kristel et al., "Overexpression of cyclin D1 indicates a poor prognosis in squamous cell carcinoma of the head and neck," Archives of Otolaryngology_Head and Neck Surgery, vol. 123, no. 5, pp. 497-502, 1997.

[27] J. Bartkova, J. Lukas, H. Müller, D. Lützhøt, M. Strauss, and J. Bartek, "Cyclin D1 protein expression and function in human breast cancer," International Journal of Cancer, vol. 57, no. 3, pp. 353-361, 1994.

[28] J. T. Castle, M. Cardinali, F. J. Kratochvil et al., "p53 and cyclin D1 staining patterns of malignant and premalignant oral lesions in age-dependent populations," Oral Surgery, Oral Medicine, Oral Pathology, Oral Radiology, and Endodontics, vol. 88, no. 3, pp. 326-332, 1999.

[29] H. Mineta, K. Miura, S. Takebayashi et al., "Cyclin D1 overexpression correlates with poor prognosis in patients with tongue squamous cell carcinoma," Oral Oncology, vol. 36, no. 2, pp. 194-198, 2000.

[30] S. Staibano, M. D. Mignogna, L. Lo Muzio et al., "Overexpression of cyclin-D1, bcl-2, and bax proteins, proliferating cell nuclear antigen (PCNA), and DNA-ploidy in squamous cell carcinoma of the oral cavity," Human Pathology, vol. 29, no. 11, pp. 1189-1194, 1998. 


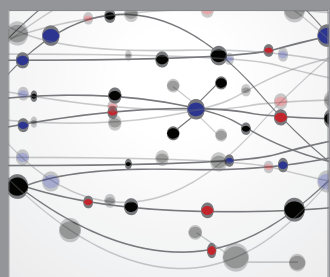

The Scientific World Journal
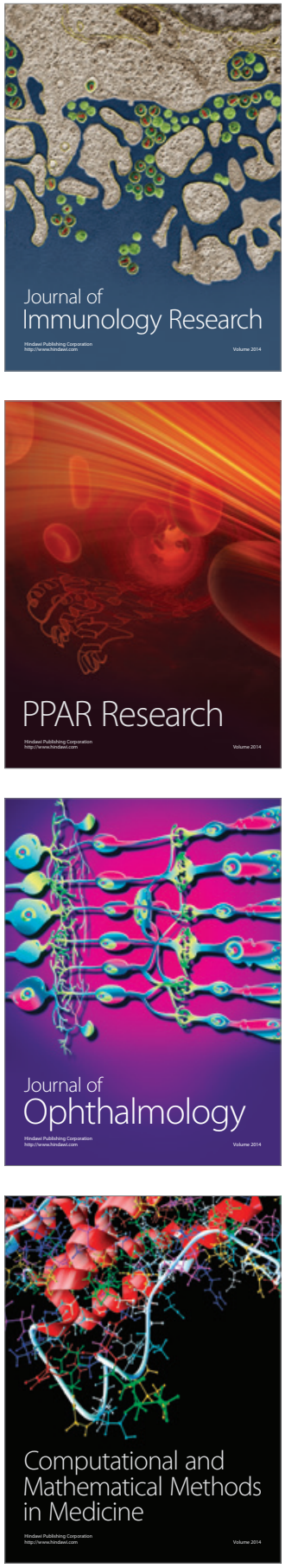

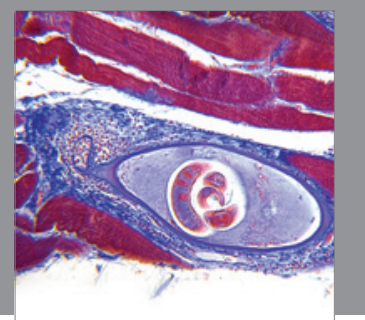

Gastroenterology

Research and Practice
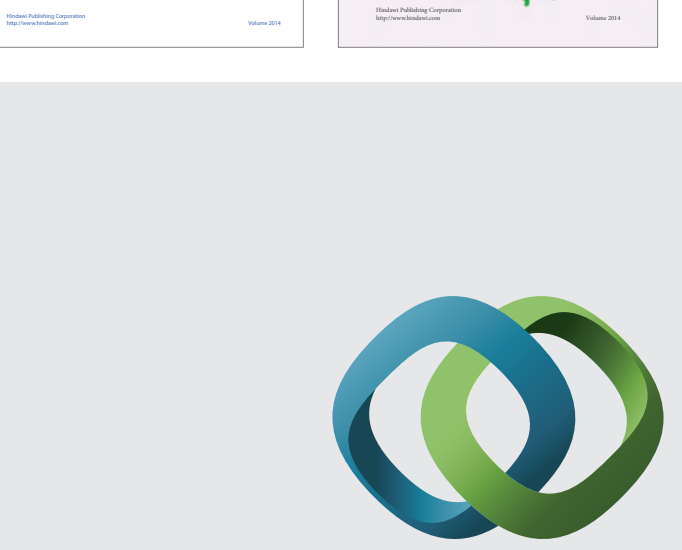

\section{Hindawi}

Submit your manuscripts at

http://www.hindawi.com
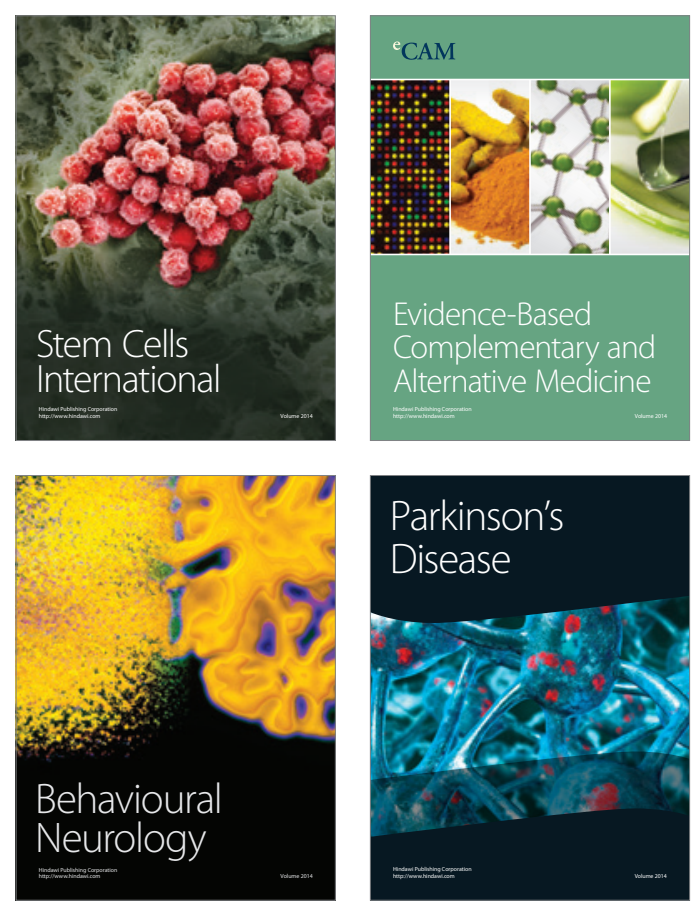

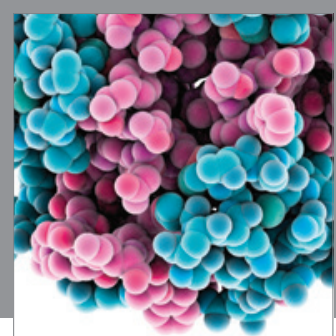

Journal of
Diabetes Research

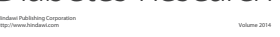

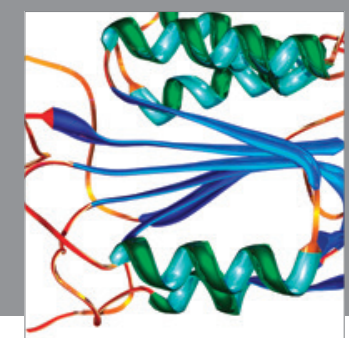

Disease Markers
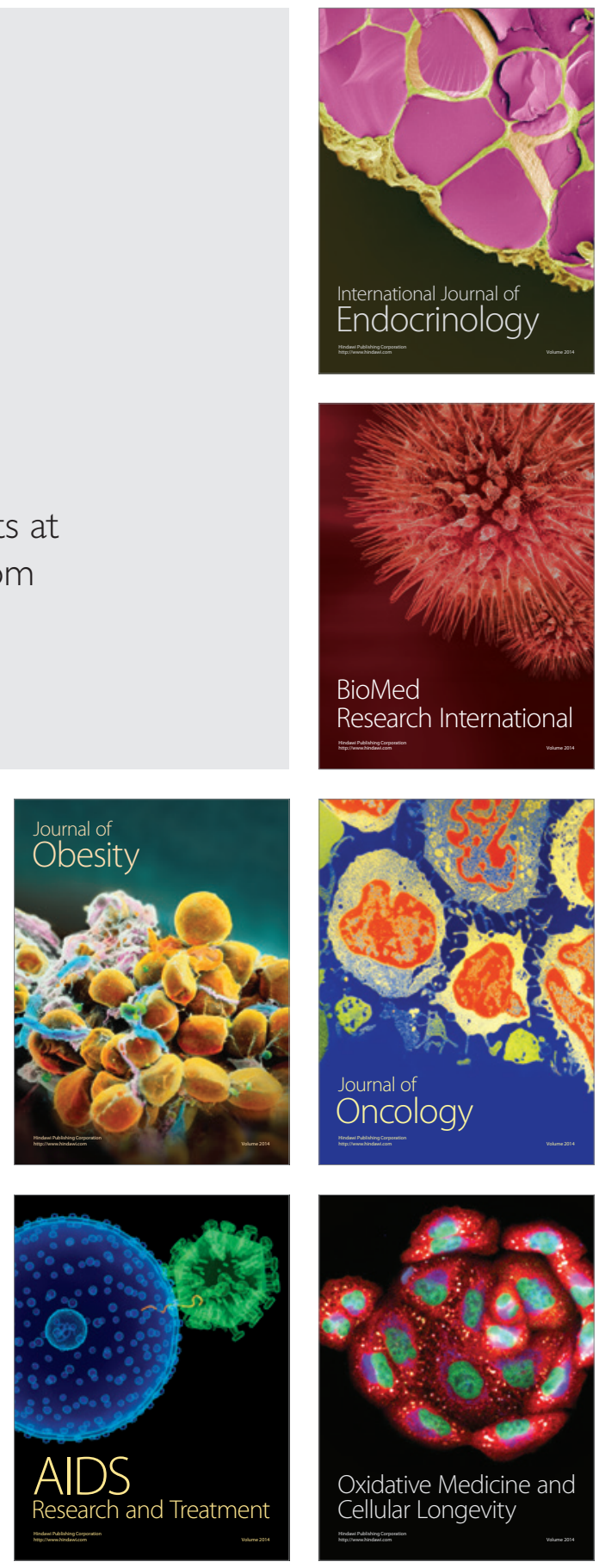